REVISTA de

PEDAGOGIE

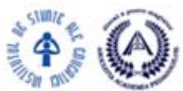

http://revped.ise.ro

Print ISSN 0034-8678; Online ISSN: 2559 - 639X

\title{
CAREER GUIDANCE IN HIGHER EDUCATION: NEEDS AND PRACTICES
}

CONSILIEREA PENTRU CARIERĂ ÎN ÎNVĂTĂMÂNTUL SUPERIOR - NEVOI ŞI PRACTICI

\section{Oana GHEORGHE, Mirela ALEXANDRU}

\author{
Journal of Pedagogy, 2017 (2), 75 - 84 \\ https://doi.org/10.26755/RevPed/2017.2/75
}

The online version of this article can be found at: http://revped.ise.ro/category/2017-en/

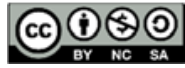

This work is licensed under the Creative Commons Attribution-NonCommercial-ShareAlike 4.0 International License. 94042, USA

Published by:

\section{INSTITUTUL DE ȘTIINTTE ALE EDUCAṬIEI}

http://www.ise.ro/

Further information about Revista de Pedagogie - Journal of Pedagogy can be found at:

Editorial Policy: http://revped.ise.ro/editorial-policy/

Author Guidelines: http://revped.ise.ro/the-writer-guide-2/ 


\section{REZULTATE ALE CERCETĂRILOR \\ CONSILIEREA PENTRU CARIERĂ ÎN ÎNVĂ ĂMÂNTUL SUPERIOR - NEVOI ŞI PRACTICI}

\section{Oana GHEORGHE* Mirela ALEXANDRU**}

\section{Rezumat}

Dezvoltarea societă ii aduce astăzi o transformare continuă a conceptului de carieră, concept ce sparge bariere de gen şi de cultură. Debutul în carieră poate fi anevoios, iar nevoile tinerilor sunt dinamice, de aceea consilierea pentru carieră este un domeniu ce evoluează continuu, adaptându-şi strategiile, metodele şi mijloacele la grupul intă.

În acest articol, s-a analizat rela ia dintre serviciile de consiliere pentru carieră, disponibile în cadrul universită ii VIA University College, din Danemarca, şi nevoile specifice ale studen ilor. De asemenea, am inten ionat să atragem aten ia asupra importan ei dezvoltării serviciilor pentru carieră, aceste servicii putând sprijini studen ii să îşi dezvolte atât competen ele profesionale, cât şi pe cele transversale, care să le permită să se adapteze mai uşor şi mai repede frecventelor schimbări apărute la nivelul pie ei muncii. Ideea realizării unei platforme on-line prin intermediul căreia să li se ofere studen ilor servicii de consiliere pentru carieră poate fi preluată şi adaptată contextului românesc. Cuvinte-cheie: carieră; consiliere; nevoi ale studen ilor; pia a muncii.

\section{Abstract}

The social development brings about ongoing transformation of the concept of „career”, overcoming gender and cultural barriers. Career start may be difficult and the youth needs are dynamic. This makes the career counselling an area that continuously evolves and adjusts its strategies, methods and tools to the target group.

This article analyses the connection between the career counselling services available at VIA College in Denmark and the specific needs of the students. We also wanted to draw attention upon the importance of developing career services, as these services can help students develop both their professional and transversal skills, enabling them to adapt more easily and faster to frequent changes of the labour market. The idea of creating a secure on-line platform to provide students with career counselling services can be taken up and adapted within the Romanian context.

Keywords: career; counselling; labour market; student needs.

Institutul de Ştiin e ale Educa iei, Bucureşti, România;

* Cercet. şt. dr.; oana@etwinning.ro

** Asist. cercet.; mirela.alexandru@ise.ro 


\section{Abordări teoretice}

Problematica asociată carierei şi consilierii pentru carieră este vastă. Consilierea acoperă diferite aspecte ale vie ii, atât în plan personal, cât şi în cel profesional, cu scopul de a ghida oamenii în identificarea direc iilor semnificative pentru fiecare individ şi cu posibil impact pozitiv asupra rela iei lor cu mediul social.

Conceptul de „carieră” vizează rolurile profesionale pe care le are o persoană, modul în care aceasta ac ionează la locul de muncă, în familie, în societate etc., precum şi varietatea de etape ascendente şi multidirec ionale prin care poate trece de-a lungul vie ii.

Consilierea pentru carieră este definită ca fiind „serviciul de a asista un individ, la orice vârstă sau moment al vie ii lui în alegerile sale profesionale sau educa ionale şi în managementul carierei” (OECD, 2004, p. 3).

Printre principalele teorii care au încercat să contureze acest concept, se numără teoria lui Holland considerată ca fiind teoria trăsătură-factor şi teoria dezvoltării (Savickas \& Super, 1960). Conform teoriei lui Holland, indivizii sunt caracteriza i ca fiind: realişti, investigativi, artişti, sociali, antreprenori sau conven ionali, iar comportamentul lor este determinat de interac iunea dintre personalitatea lor şi mediu (Patton, 2006).

În jurul anilor 1960, Super a elaborat teoria dezvoltării bazată pe conceptul de sine a evolu iei în carieră, care la început era asociată cu teoriile dezvoltării, însă revizuirile aduse ulterior unifică psihologia vârstelor cu teoria rolului social, pentru a creiona o imagine comprehensivă a carierelor cu multiple roluri împreună cu determinan ii şi interac iunile (Savickas \& Super, 1996, p. 126). Dintre teoriile recente privind consilierea pentru carieră amintim teoria haosului, adaptată la dezvoltarea carierei. Conform acesteia, indivizii sunt „complecşi, dinamici, neliniari, unici, emergen i, sisteme deschise de motiva ie care interac ionează cu un mediu care cuprinde sisteme cu caracteristici similare". Astfel, parcursul profesional depinde de interac iunea individ - mediu (Pryor \& Bright, 2003, p. 123).

Pentru a eviden ia dimensiunea practică vizată în cercetare, vom face o scurtă analiză a practicilor de consiliere pentru carieră: prima dintre acestea şi foarte des folosită este consilierea individuală ce presupune „o interac iune personală între consilier şi client, în cadrul căreia consilierul asistă clientul în rezolvarea problemelor mentale, emo ionale, sociale" sau de carieră (Ploşca \& Mois, 
2001, p. 10); o altă practică, la fel de utilizată este consilierea de grup, care presupune „o rela ionare a consilierului cu un grup ai cărui membri au o problemă comună” (Ploşca \& Mois, 2001, p. 11). Astăzi, practicile intens utilizate, cu impact mare asupra dezvoltării perspectivelor de carieră a studen ilor sunt: atelierele, cursurile, voluntariatul, târgurile profesionale, vizitele, programele de practică, training-uri, coaching-ul, mentoratul, programele trainee şi consilierea asistată de calculator.

\section{Sistemul de consiliere danez}

Conform Ministerului Educa iei din Danemarca, furnizarea de servicii de orientare şcolară, profesională şi personală este o prioritate, făcându-se eforturi sistematice pentru asigurarea accesibilită ii şi a calită ii acestora. Astfel, în urma reformei serviciilor de consiliere din 2008 , s-a renun at la cabinetele de consiliere din cadrul institu iilor de învă ământ, responsabilitatea pentru acest tip de servicii revenind centrelor de consiliere municipale şi regionale, $\mathrm{cu}$ angaja i specializa i în consiliere şi orientare în carieră (CEDEFOP, 2009). Ministerul Educa iei şi Ministerul Învă ământului Superior şi Ştiin elor coordonează sistemul de consiliere şi orientare danez, care cuprinde 52 de centre de consiliere pentru tineri, 7 centre regionale şi 13 centre de consiliere pentru adul i (UMV, 2011).

Centrele de orientare pentru tineri oferă servicii de orientare pentru persoanele până în 25 de ani, punând accent pe trecerea de la învă ământul obligatoriu la cel post-obligatoriu sau spre pia a muncii. Atât pentru studen i, cât şi pentru tineri şi adul i din afara sistemului de învă ământ, sunt disponibile serviciile centrelor de orientare regionale (Studievalg).

De asemenea, există centre de consiliere pentru adul i care oferă consiliere acestora pentru învă area pe tot parcursul vie ii. Pentru dezvoltarea perspectivelor de ac iune a consilierii a fost lansat în ianuarie 2011, sistemul informatic „E-guidance”, accesibil oricărei persoane interesate.

În cadrul universită ilor, serviciile de consiliere pentru carieră iau forma târgurilor pentru carieră organizate o dată la doi ani, a sesiunilor de consiliere individuale oferite de consilierul specializării şi a sesiunilor de grup, care au ca scop dezvoltarea de abilită i de marketing personal, însă acestea sunt disponibile doar după absolvire. În afara universită ilor, studen ii pot beneficia de consiliere pentru carieră prin intermediul platformei na ionale de consiliere, a site-ului universită ii, dar şi a centrelor de consiliere regionale. 


\section{Metodologia cercetării}

Prin intermediul acestei cercetări ne-am propus să investigăm nevoile de consiliere în carieră a studen ilor înscrişi la programul de licen ă, specializările Pedagogie (Pædagoguddannelsen) şi Lucrător social (Socialrådgiveruddannelsen) la Universitatea VIA University College, Holstebro, Danemarca, precum şi percep ia celor implica i (studen i şi consilieri) asupra serviciilor de consiliere pentru carieră disponibile. Cercetarea s-a bazat atât pe metode calitative (ancheta pe bază de interviu şi analiza de documente), cât şi pe metode cantitative (ancheta pe bază de chestionar).

Identificarea nevoilor studen ilor privind consilierea pentru carieră şi a percep iei acestora şi a consilierilor asupra serviciilor disponibile a pornit de la presupozi ia că serviciile de consiliere pentru carieră sunt apreciate de către studen i ca fiind importante pentru viitorul lor parcurs profesional, aceştia dorind o îmbunătă ire a serviciilor din cadrul universită ii în direc ia diversificării şi corelării cu nevoile lor specifice.

Chestionarul a fost aplicat pe un lot de 101 studen i, cu vârste cuprinse între 18 şi 43 de ani, afla i în programele de studiu Pedagogie socială şi Lucrători sociali ale VIA University College, Holstebro, Danemarca şi a fost compus din 17 întrebări (dintre care 4 închise, 12 semi-închise şi una deschisă). Acesta a fost aplicat atât în format tipărit, în cadrul întâlnirilor cu studen ii, cât şi în format electronic, cu ajutorul Google Forms, transmis prin intermediul canalelor de comunicare ce utilizează tehnologiile informatice. Chestionarul a urmărit să culeagă date privind participarea studen ilor la serviciile de consiliere pentru carieră disponibile, percep ia despre acestea şi nevoile studen ilor în raport cu consilierea pentru carieră.

Interviul realizat cu consilierii a fost semi-structurat şi a durat aproximativ 30 de minute, urmărind colectarea de informa ii privind percep ia asupra sistemului actual de consiliere pentru carieră din Danemarca, identificarea serviciilor accesibile studen ilor şi specificul acestora.

Au fost, de asemenea, analizate diferite documente legislative, studii şi rapoarte pentru fundamentarea teoretică a subiectului investigat.

\section{Rezultatele cercetării}

Din prima etapă a studiului reiese că o propor ie covârşitoare de studen i (95\%) consideră că au nevoie de consiliere pentru carieră pe durata studiilor universitare, cu precădere în ultimul an al ciclului de licen ă (40\%). Responden ii 
au men ionat nevoi privind orientarea pentru a face fa ă cu succes unui interviu $(28 \%)$, orientarea pentru scrierea CV-ului şi a scrisorii de inten ie $(23 \%)$, orientarea pentru viitorul traseu profesional (16\%), dezvoltarea şi/sau descoperirea de abilită i (14\%), managementul carierei (9\%), alegerea unui loc de muncă $(4 \%)$, continuarea studiilor (3\%) şi altele precum punerea în practică a no iunilor teoretice (3\%).

Aceste date arată importan a consilierii pentru carieră în mediul universitar şi orientarea studen ilor către construc ia sinelui profesional, către abilitarea pentru pia a muncii atât la nivel de competen e profesionale, cât şi la nivel de abilită i de marketing personal.

S-a constatat, de asemenea, că există o corela ie între nevoile identificate şi dimensiunile pe care consideră studen ii că ar trebui să le abordeze consilierea pentru carieră, cea mai importantă dimensiune fiind dezvoltarea abilită ilor de promovare personală (în foarte mare măsură 61\%), urmată de cea care vizează sprijinul pentru planificarea carierei, identificarea, explorarea şi evaluarea alternativelor pentru alegerea unui traseu profesional (în foarte mare măsură $37 \%$ ). La polul opus se află variabila continuarea studiilor, $38 \%$ dintre studen i fiind de părere că nu este foarte important ca serviciile de consiliere pentru carieră să vizeze acest aspect.

S-a urmărit, de asemenea, identificarea perspectivei responden ilor (studen i şi consilieri) fa ă de platforma informatică de consiliere, mai precis fa ă de utilitatea acesteia. Astfel în urma studiului reiese faptul că platforma are un real succes, studen ii considerând-o foarte utilă şi adaptată realită ii lor (35\%), uşor de utilizat (12\%), iar consilierii definind-o ca pe o ,adevărată sursă de inspira ie". Deşi ambele categorii de responden i sus in că platforma este de un real folos şi uşor de utilizat, totuşi, atrag aten ia asupra riscului de „mecanizare a interac iunilor interpersonale” (46\%). Ei sus in că este important să existe un echilibru între sesiunile fa ă în fa ă şi sesiunile mijlocite de mediul on-line pentru a păstra specificul personalizat al consilierii pentru carieră.

Foarte important de specificat este faptul că există discordan ă între ceea ce consideră consilierii că ar trebui să abordeze în sesiunile de orientare pentru carieră şi nevoile specifice ale studen ilor. În urma interviurilor a reieşit că specialiştii pun accentul pe consilierea educa ională şi pe planificarea demersului profesional, în timp ce studen ii reclamă o nevoie foarte mare de servicii de consiliere pentru carieră. Din acest motiv, rata de participare la sesiunile de consiliere pentru carieră este foarte scăzută, doar 32\% dintre studen ii responden i afirmând că au participat la aceste sesiuni. 
Ultima parte a studiului a urmărit determinarea gradului de satisfac ie a studen ilor cu privire la serviciile de consiliere pentru carieră oferite de universitate. Majoritatea responden ilor (40\%) consideră că serviciile actuale răspund în foarte mică măsură nevoilor lor, în timp ce doar 4\% dintre aceștia afirmă că sunt foarte mul umi i.

Tratând în paralel percep iile celor două categorii de responden i, consilieri şi studen i, se poate observa discordan a la nivelul direc iei de ac iune a serviciilor de consiliere pentru carieră. Astfel, consilierii pun accentul pe consilierea educa ională, în timp ce studen ii percep nevoia abilitării lor cu strategii de marketing personal în vederea facilitării accesului lor la pia a muncii.

Interesul scăzut al studen ilor pentru sesiunile de consiliere (32\%) este pus de către consilieri pe seama faptului că VIA University College este o universitate profesională, în strânsă legătură cu pia a muncii. Totuşi, studiul realizat asupra studen ilor relevă un interes crescut fa ă de servicii de consiliere pentru carieră, cu condi ia ca acestea să răspundă nevoilor acestora.

În raport cu întregul sistem danez, serviciile de consiliere pentru carieră facilitate studen ilor chestiona i urmează aceleaşi perspective care pun accent pe consilierea educa ională şi sus in continuarea studiilor, toate acestea venind în sprijinul politicii na ionale axate pe creşterea procentului de adul i cu studii superioare. De asemenea, consilierii sus in că serviciile de consiliere pentru carieră în VIA University sunt servicii secundare, de acest tip de servicii putându-se beneficia, cu precădere, după finalizarea studiilor.

Analizând în ansamblu rezultatele cercetării putem spune că atât studen ii, cât şi consilierii nu sunt pe deplin mul umi i de sistemul de consiliere pentru carieră. Consilierii consideră că sunt în deficit de personal, că nu există oameni special pregăti i pentru facilitarea serviciilor de consiliere pentru carieră, iar singurul consilier al specializării este nevoit să răspundă tuturor cererilor studen ilor, fie ele de natură educa ională, de carieră sau personală. În vederea îmbunătă irii serviciilor actuale, atât studen ii cât şi consilierii sus in înfiin area unui centru de consiliere pentru carieră în cadrul VIA University College, Holstebro (34\%) cu mai mul i angaja i (comparativ cu situa ia actuală, un angajat pe specializare).

Pentru a explora posibilită ile de dezvoltare a serviciilor de consiliere pentru carieră, studen ii au fost chestiona i cu privire la activită ile/evenimentele care ar trebui să se deruleze prin intermediul serviciilor de consiliere pentru carieră. Pe lângă serviciile clasice de consiliere individuală şi de grup, studen ii au arătat un interes crescut fa ă de ateliere de lucru şi de formare în vederea 
dezvoltării competen elor necesare, precum şi fa ă de evenimente precum târgurile de cariere.

Din răspunsurile oferite de responden i se poate constata tendin a de abordare a consilierii ca o experien ă de învă are interactivă şi colaborativă. Serviciile de consiliere pentru carieră sunt esen iale pentru inser ia cât mai facilă a studen ilor pe pia a muncii, cu atât mai mult în cazul absolven ilor VIA University College, care este o universitate profesională. Specializarea într-un domeniu impune dezvoltarea abilită ilor de marketing personal, a abilită ilor şi competen elor transversale în vederea creşterii şanselor de angajare a studentului şi de adaptare a acestuia la cerin ele locului de muncă şi la dinamica pie ei muncii.

\section{Recomandări}

La nivelul Universită ii din Bucureşti, serviciile de consiliere pentru carieră revin Departamentului de Consiliere şi Orientare pentru Carieră, care are în subordonarea sa Centrul de Informare, Orientare şi Consiliere Profesională şi Biroul Rela ia cu Pia a Muncii. Ideea platformei on-line dedicată serviciilor de consiliere pentru carieră poate fi preluată şi în România, aceasta putând fi administrată, de exemplu, de Centrul de Informare, Orientare şi Consiliere Profesională a Studen ilor din cadrul Universită ii din Bucureşti. Angaja ii centrului ar putea lucra fie cu jumătate de normă în mediul fizic şi jumătate de normă pe platforma on-line, fie unii dintre aceştia vor lucra exclusiv pe platformă. Acest lucru devine necesar, având în vedere structura platformei propuse, respectiv, oferta pentru consiliere facilitată de mesageria on-line, telefon şi e-mail.

Necesitatea dezvoltării serviciilor de consiliere pentru carieră în România reiese din studiul ANOSR realizat pe un eşantion de 20.000 de studen i. Astfel, un procent mai mare de $80 \%$ din responden ii chestiona i se declară nemul umi i de serviciile de consiliere pentru carieră oferite pe parcursul studiilor universitare. Acelaşi studiu relevă faptul că doar un procent de 10,6\% dintre studen i au participat la sesiuni de consiliere pentru carieră. Procentul scăzut de tineri care accesează serviciile de consiliere pentru carieră poate fi corelat cu rata crescută a şomajului în rândul tinerilor (25\% în 2015), putând fi considerat ca factor de influen ă negativă asupra gradului de ocupare al tinerilor.

Un alt argument în favoarea implementării unui astfel de proiect este sincronizarea domeniului consilierii pentru carieră cu evolu iile tehnologiei şi cu tendin a tinerei genera ii deoarece, conform unui studiu MEDIAFAX din 2016, 97\% dintre tinerii cu vârste cuprinse între 16 şi 24 de ani accesează zilnic internetul. 
Studiul de fa ă lasă deschise perspective de cercetare atât de necesare pentru îmbogă irea bazei teoretice şi metodologice a consilierii pentru carieră în România.

Date fiind rezultatele şi impactul pe care implementarea unui astfel de serviciu de consiliere on-line le-a generat, dar şi popularitatea de care se bucură acesta, considerăm că o adaptare la sistemul românesc, va sus ine dezvoltarea serviciilor de consiliere. De asemenea, este important să specificăm faptul că impactul şi rezultatele posibile asupra realită ii româneşti nu sunt garantate de succesul experien ei daneze, ci sunt dependente de metodologia de implementare, de strategiile de transferabilitate şi de adaptare la context şi, nu în ultimul rând, de îmbinarea acestei practici cu altele precum consilierea individuală, consilierea de grup sau târguri de carieră pentru a maximiza impactul şi eficien a procesului de consiliere.

Dezvoltarea sistemului de formare ini ială şi continuă, dinamica pie ei muncii precum şi evolu ia tehnologică influen ează substan ial procesul parcurs de la formare la angajare, proces ce poate fi destul de anevoios pentru mul i dintre studen i. Serviciile de consiliere pentru carieră pot sprijini studen ii, abilitându-i atât cu competen ele specifice desfăşurării unei profesii, cât şi cu competen e transversale care să le permită să se adapteze mai uşor şi mai repede la frecventele schimbări apărute la nivelul pie ei muncii.

Abordarea problematicii carierei în procesul de consiliere a devenit, după cum reiese din diferite studii, o nevoie pregnantă în rândul studen ilor, nevoie determinată pe de o parte de competitivitatea crescută din pia a muncii, iar pe de altă parte de dorin a de evolu ie personală şi profesională. Astfel, consilierea pentru carieră trebuie realizată în mediul universitar, nu ca un serviciu secundar, accesat doar în cazuri de nevoie extremă, ci ca o practică uzuală a studen ilor, pentru a le oferi acestora posibilitatea de a în elege multidimensionalitatea dezvoltării lor în rela ie cu realitatea lumii în care trăiesc şi performează, în scopul integrării func ionale şi, implicit, pentru a în elege direc iile multiple de ac iune ale acestui domeniu oferit, a beneficiilor pe care acesta le aduce, atât la nivelul construc iei şi şlefuirii sinelui profesional, cât şi la nivelul dezvoltării personale.

\section{Concluzii}

Studen ii sunt interesa i de serviciile de consiliere pentru carieră, acest interes venind însă, cu anumite nevoi specifice, nu întotdeauna satisfăcute de serviciile de consiliere pentru carieră disponibile. Faptul că serviciile de consiliere în carieră nu răspund nevoilor studen ilor este cauzat, conform consilierilor, pe 
de o parte de lipsa personalului calificat, iar pe de altă parte de direc iile de ac iune ale sistemului de consiliere danez axat pe consilierea educa ională. Astfel, cea mai mare provocare a sistemului de consiliere danez este aceea de a stabili un echilibru între serviciile de consiliere educa ională şi cele de consiliere pentru carieră.

Literatura ambiguă care tratează tematica serviciilor de consiliere pentru carieră, precum şi resursele bibliografice limitate în limba engleză care prezintă sistemul de consiliere din Danemarca au reprezentat unele dintre limitele documentării pentru fundamentarea cercetării.

De asemenea, dat fiind că cercetarea a fost realizată pe un număr restrâns de responden i, şi nu pe un eşantion reprezentativ, face ca rezultatele să nu poată fi extrapolate, generalizate pentru întregul sistem de învă ământ superior danez. Acestor limite li se adaugă resursele umane, de timp sau financiare limitate.

Dezvoltarea serviciilor de consiliere pentru carieră este necesară, mai ales că pia a muncii este foarte dinamică, iar competen ele transversale sunt din ce în ce mai vizate. Consilierul pentru carieră poate favoriza şi sus ine dezvoltarea acestor competen e şi poate ajuta studentul să ob ină mai uşor un loc de muncă potrivit şi să se adapteze la schimbările din pia a muncii. Astfel, se recomandă înfiin area unui centru de consiliere pentru carieră, care să vizeze aspectele generale ale consilierii pentru carieră, pornindu-se de la nevoile studen ilor înscrişi la programele de studiu ale universită ii.

Se recomandă, de asemenea, utilizarea mai frecventă a consilierii de grup, care favorizează socializarea şi îi ajută pe studen i să conştientizeze faptul că nu sunt singurii care se confruntă cu situa ii problemă legate de carieră. De asemenea, studen ii simt nevoia de a participa la ateliere de lucru şi de dezvoltare a abilită ilor de marketing personal, precum şi la sesiuni de consiliere individuală.

\section{REFERIN E BIBLIOGRAFICE}

Agen ia Na ională pentru Ocuparea For ei de Muncă. (2013). Strategia na ională de ocupare a for ei de muncă2014-2020.

http://www.anofm.ro/strategia-agen\%C5\%A3iei-na\%C5\%A3ionale-pentruocuparea-for\%C5\%A3ei-de-munc\%C4\%83-2014-2020.

ANOSR. (2011). Serviciile de consiliere pentru carieră. Perspectiva ANOSR. www.anosr.ro.

CEDEFOP. (2009). Denmark - VET in Europe. Country Report. 
http://www.cedefop.europa.eu/en/publications-and-resources/country-reports/ denmark-vet-europe-country-report-2009.

Euroguidance. (2014). Guidance in Denmark. The educational guidance system in Denmark, Copenhaga: The Danish Agency for Higher Education.

OECD. (2004). Draft Resolution of Council and of the representatives of Member States meeting within the Council of Strengthening Policies, Systems and Practices in field of Guidance throughout life in Europe. Luxembourg: Publications Office of the European Union.

Patton, W. (2006). Overview of career development theory. Connecting theory and practice, Rotterdam: Sense Publishers.

Ploşca , M., \& Mois, A. (2001). Consiliere privind cariera - aplica ii în şcoală. Cluj-Napoca: Editura Dacia.

Pryor R. G. L., \& Bright J. E. H. (2014). The Chaos Theory of Careers (CTC). Ten years on and only just begun. Australian Journal of Career Development, $14-25$.

Savickas, M., \& Super A. (2005). The theory and practice of career construction. In S. D. Brown \& R. T. Lent (Eds.), Career development and counseling: Putting theory and research to work. Hoboken: NJ: Wiley.

UMV. (2011). Youth Guidance Centres.

http://www.eng.uvm.dk/Uddannelse/Educational\%20and\%20vocational $\% 20$ guida.

UMV. (2011). Guidance.: http://www.eng.uvm.dk.

The online version of this article can be found at: http://revped.ise.ro/category/2017-en/

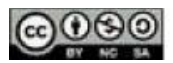

This work is licensed under the Creative Commons Attribution-NonCommercial-

ShareAlike 4.0 International License.

To view a copy of this license, visit http://creativecommons.org/licenses/by-ncsa/4.0/ or send a letter to Creative Commons,

PO Box 1866, Mountain View, CA 94042, USA.
Versiunea online a acestui articol poate fi găsită la: http://revped.ise.ro/category/2017-ro/

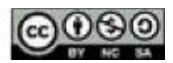

Această operă este pusă la dispozi ie sub licen a Creative Commons AttributionNonCommercial-ShareAlike 4.0 International.

Pentru a vedea o copie a acestei licen e, vizita $i$ http://creativecommons.org/licenses/by-ncsa/4.0/ sau trimite i o scrisoare către Creative Commons, PO Box 1866, Mountain View, CA 94042, SUA. 